\title{
Alimentação e nutrição de Pirapitinga (Piaractus brachypomums) e Tambaqui (Colossoma macropomum): Revisão
}

\author{
Fagner Machado Ribeiro ${ }^{*}$, Paulo Vitor Divino Xavier Freitas ${ }^{1}$, Everton Oliveira dos \\ Santos $^{2}$, Reginaldo Martins de Sousa ${ }^{2}$, Thony Assis Carvalho ${ }^{3}$, Emizael Menezes de \\ Almeida ${ }^{4}$, Tâina Oliveira dos Santos ${ }^{5}$, Adriano Carvalho Costa ${ }^{6}$ \\ ${ }^{I}$ Mestrando em Zootecnia, Instituto Federal Goiano - Campus Rio Verde, (IF Goiano), Rio Verde, GO, Brasil. \\ ${ }^{2}$ Graduado em Zootecnia, Instituto Federal Goiano - Campus Ceres, (IF Goiano), Ceres, GO, Brasil. \\ ${ }^{3}$ Professor Doutor - Departamento de Zootecnia, Instituto Federal Goiano - Campus Ceres, (IF Goiano), Ceres, GO, Brasil. \\ ${ }^{4}$ Mestrando em zootecnia, Universidade Federal de Goiás - EVZ, (UFG), Goiânia, GO, Brasil. \\ ${ }^{5}$ Acadêmica do curso de zootecnia, Instituto Federal Goiano - Campus Ceres, (IF Goiano), Ceres, GO, Brasil. \\ ${ }^{6}$ Professor Doutor - Departamento de Zootecnia, Instituto Federal Goiano - Campus Rio Verde, (IF Goiano), Rio Verde, GO, \\ Brasil. \\ *Autor correspondente: fagnermr@hotmail.com
}

RESUMO. A aquicultura brasileira dispõe de grande diversidade de espécies nativas com potencial de cultivo em função da vasta biodiversidade das distintas bacias hidrográficas. Em razão dos custos com alimentação e da importância das espécies Colossoma macropomum e Piaractus brachypomus para a aquicultura brasileira, é indispensável o conhecimento das exigências nutricionais e fatores que podem influenciar a elaboração de rações balanceadas que permitam adequado desempenho produtivo do tambaqui e pirapitinga. Objetivou-se revisar resultados de pesquisas relacionados a nutrição de Colossoma macropomum e Piaractus brachypomus. Na literatura científica, as publicações se concentram na determinação das exigências nutricionais de proteína, energia e suas relações. São escassas avaliações direcionadas à determinação de exigências de aminoácidos, ácidos graxos essenciais, minerais e vitaminas, visto que, em sua maior parte, as dietas praticas fornecidas à essas espécies são formuladas utilizando exigências determinadas para espécies exóticas. A digestibilidade das frações proteicas e da energia de ingredientes comumente utilizados na alimentação de peixes nativos deve ser melhor esclarecida. Ainda a possibilidade de inclusão de alimentos alternativos na alimentação desses peixes deve ser avaliada, principalmente na espécie Piaractus brachypomus. Entre as espécies estudas foi a que apresentou maior carência de informações. Necessita-se aprofundar o conhecimento da utilização de lipídeos e carboidratos como fontes de energia, resultando em possível redução do nível proteico das rações. Os níveis apropriados de proteína e energia das rações são divergentes, havendo a necessidade de padronização dos experimentos.

Palavras chave: Aquacultura, nutrientes, peixes

\section{Food and nutrition Pirapitinga (Piaractus brachypomums) and Tambaqui (Colossoma macropomum): Review}

\begin{abstract}
Brazilian aquaculture offers great diversity of native species with potential for cultivation due to the wide biodiversity of different river basins. Because of feeding costs and the importance of species Colossoma macropomum and Piaractus brachypomus for Brazilian aquaculture is essential knowledge of nutritional requirements and factors that may influence the development of balanced rations that allow adequate productive performance of Tambaqui and Pirapitinga. This study aimed to review research results related to nutrition Colossoma macropomum and Piaractus brachypomus. In the scientific literature, publications focus on determining the nutritional requirements of protein, energy and their relationships. They are scarce reviews aimed at determining the amino acid requirements; essential fatty acids, minerals and vitamins, since, for the most part, the diets
\end{abstract}


practices provided to these species are formulated using certain requirements for exotic species. The digestibility of protein fractions and energy commonly used ingredients in feeding native fish should be better clarified. Even the possibility of inclusion of alternative food in the feeding of these fish should be evaluated, especially in species Piaractus brachypomus. Among the studied species it showed the greatest lack of information. We need to deepen the knowledge of the use of lipids and carbohydrates as energy sources, resulting in possible reduction of the protein level of feed. The appropriate levels of protein and energy rations are different, there is the need for standardization of the experiments.

Keywords: Aquaculture, nutrients, fish

\section{Introdução}

O Brasil apresenta importante potencial aquícola, com costa marítima de aproximadamente $8.500 \mathrm{~km}$ e 5.500 ha de reservatórios de água doce. No último senso aquícola foi relatado produção nacional de pescado, incluindo pesca e aquicultura de 1,43 milhões de toneladas (Brasil, 2011). Essa atividade pesqueira gera um PIB nacional de $\mathrm{R} \$ 5$ bilhões, mobilizam 800 mil profissionais e proporciona 3,5 milhões de empregos diretos e indiretos (Brasil, 2014).

Uma característica importante da piscicultura brasileira é a diversidade de espécies. O Brasil possui 12 bacias hidrográficas distribuídas em distintas regiões com características climáticas particulares, sendo elas: Bacia Amazônica, Tocantins Araguaia, Paraguai, Paraná, Parnaíba, São Francisco, Bacia Atlântico Nordeste Ocidental, Atlântico Nordeste Oriental, Atlântico Leste, Atlântico Sudeste, Atlântico Sul e Bacia do Uruguai (Brasil, 2014).

Com toda essa diversidade de ambientes é natural que ocorram inúmeras espécies distribuídas, entre as quais, utilizam-se comercialmente, mais de 30 espécies, com os mais variados hábitos alimentares e ambientes de criação.

Dentre as espécies com potencial de cultivo, que preenchem os requisitos necessários e adequados para a piscicultura, merecem destaque as que apresentam potencial para a piscicultura intensiva. Espécies que possuem carne de excelente qualidade, facilidade de adaptação ao cultivo em tanques ou viveiros e grande utilidade na pesca esportiva são preferíveis. Todavia, pesquisas no âmbito da nutrição relacionadas à adequação nutricional para cada uma das espécies são esparsas.

As espécies nativas tanto no ambiente natural quanto no cativeiro, exigem diferentes nutrientes para manutenção de suas atividades fisiológicas normais. Proteína e energia assumem grande importância na composição de dietas para peixes com maior destaque para a fração proteica, que é exigida em quantidades elevadas. A relação energia/proteína da dieta interfere de forma expressiva na determinação da concentração ótima de proteína em rações para peixes. Dessa forma, é importante que sejam estabelecidos os níveis adequados de proteína, bem como das relações energia/proteína (Boscolo et al., 2011).

Há grande complexidade para nutricionistas em definir a nutrição adequada para os peixes nativos brasileiros devido ao grande número de espécies com potencial de cultivo. As características ambientais e variações climáticas do país fazem com que estas espécies tenham características de adaptação ambiental convenientes à sua região hidrográfica, o que dificulta ainda mais as pesquisas e incentiva o cultivo de determinada espécie. Outro fator que dificulta a determinação das exigências nutricionais de espécies é a realização de hibridismo interespecífico, hoje muito praticado no Brasil.

Entre as espécies de peixes que tem suas exigências quantitativas determinadas para os dez aminoácidos essenciais (AAE), prevalece que todas elas são espécies exóticas, entre elas a carpa (Cyprinus carpio), tilápia do Nilo (Oreochromis niloticus), truta arco Íris (Oncorhynchus mykiss), bagre norte americano (Ictalurus punctactus) e salmão (Oncorhynchus spp.) (Vásquez-Torres \& Arias-Castellanos, 2013). Neste sentido, a necessidade de desenvolver tecnologias que viabilizem a produção de espécies nativas tem levado os pesquisadores brasileiros a constantes estudos, especialmente em relação à alimentação e nutrição de peixes (Abimorad et al., 2007).

Diante disso, objetivou-se revisar trabalhos científicos relacionados à alimentação e nutrição de serrasalmideos, nativos, brasileiros, 
especialmente Colossoma macropomum $e$ Piaractus brachypomus, visto que este é um fator de grande influência no cultivo dessas espécies.

\section{Revisão de Literatura}

\section{Tambaqui (Colossoma macropomum)}

Originário da América do Sul, das bacias dos rios Amazonas e Orinoco, o tambaqui, Colossoma macropomum é uma espécie de peixe da classe Osteichthyes, subclasse Actinopterygii, ordem Characiformes, família Characidae e subfamília Myleinae (Dairiki \& Silva, 2011). O tambaqui é o segundo maior peixe de escamas do Brasil. Além de ser uma das espécies de peixe mais importantes para a economia da Amazônia, é a espécie nativa mais cultivada na Amazônia brasileira e a mais frequente em pisciculturas de todo o país (LoperaBarreto et al., 2011).

O cultivo do tambaqui no país é mais frequente nas regiões Norte, Centro-Oeste e Nordeste, onde além da ampla aceitação pelo mercado consumidor, há características climáticas favoráveis para o seu desenvolvimento. Em regiões aonde a temperatura da água chega abaixo de $17^{\circ} \mathrm{C}$ o cultivo dessa espécie tem desanimado os piscicultores. A facilidade de obtenção de juvenis, bom potencial de crescimento, alta produtividade e rusticidade justifica o crescente interesse pelo cultivo dessa espécie (Rodrigues, 2014).

De acordo com Lopera-Barreto et al. (2011) o tambaqui é um excelente filtrador, sendo que na fase larval sua alimentação é baseada na ingestão de zooplâncton, passando a consumir pequenas sementes e invertebrados nas fases de alevino e juvenil. Como várias espécies nativas o tambaqui tem grande capacidade de adaptação em relação à alimentação, com capacidade de digerir proteína de origem animal e vegetal (Silva et al., 2003).

Naturalmente, a dieta do tambaqui é composta prioritariamente de frutos e sementes no período de enchente. Em época de vazante, com a redução na disponibilidade de alimento, passa a se alimentar de zooplâncton, motivo pelo qual seu hábito alimentar é frequentemente denominado de onívoro-oportunista. Também fazem parte da dieta do tambaqui macrófitas, insetos, algas, moluscos e peixes (Rodrigues, 2014).

\section{Pirapitinga (Piaractus brachupomus)}

Essa espécie é considerada a terceira maior entre os peixes de escamas da Amazônia. Chega a atingir $0,8 \mathrm{~m}$ de comprimento e pesar $20 \mathrm{Kg}$. É natural dos rios Amazonas, Solimões, Orinoco e respectivos afluentes. Possui hábito alimentar onívoro, naturalmente se alimentam de frutas, sementes, folhas e microcrustáceos (Lima, 2014).

O Piaractus brachypomus apresenta características corporais que atraem o mercado consumidor, como menor dimensão de cabeça, facilidade para descamar e ainda algumas particularidades como coloração das regiões peitoral e opérculos avermelhados e demais partes do corpo prateadas que atraem a atenção do consumidor. Ainda possui atributos produtivos como rápido crescimento, rusticidade, resistência a elevadas temperaturas da água de viveiros, a baixos níveis de oxigênio dissolvido, ao manuseio e a enfermidades (Chagas et al., 2005).

Costa (2015) relatou que características de coloração das espécies tambaqui, pacu e pirapitinga podem ser influenciados pelo ambiente de cultivo e pelo estresse a que são submetidos durante esse. Ambientes de cultivo com alta densidade de estocagem e baixa renovação de água geram maior estresse e como consequência proporciona coloração diferenciada.

Esse mesmo autor observou alta taxa de erro $(51,13 \%)$ na identificação da composição genética de Serrasalmideos, por parte de piscicultores, ao comercializarem alevinos das espécies tambaqui, pacu, pirapitinga e seus híbridos, quando classificados através da avaliação fenotípica. Esta inconfiabilidade na identificação dos peixes pode influenciar negativamente o manejo produtivo das pisciculturas comerciais, bem como os resultados de pesquisas que envolvem a nutrição e alimentação de peixes redondos, pelo desconhecimento da espécie em questão.

\section{Proteína}

A proteína, por ser um dos nutrientes mais onerosos da dieta, tem recebido especial atenção com relação às pesquisas de exigências nutricionais, por influenciar diretamente o crescimento e o desenvolvimento dos peixes (Santos et al., 2010). Animais adultos apresentam exigência proteica inferior e de energia superior à verificada para animais jovens.

A retenção de proteína para o crescimento é a meta a ser alcançada pelos nutricionistas de rações para peixes, buscando dessa forma uma ração economicamente viável e ambientalmente sustentável. A adequação exata do nível de 
proteína, a qualidade da fonte proteica e a disponibilidade de fontes energia não proteicas são fundamentais para maximizar a utilização da fração proteica da dieta para o crescimento (Neves et al., 2015).

Em virtude da oferta de alimento natural sazonal, em ambiente natural, o Colossoma macropomum apresenta capacidade de realização do "efeito poupador de proteína". Nessas condições, essa espécie utiliza de forma mais eficiente a proteína para mantença, reparo de tecidos e crescimento, reduzindo sua utilização como fonte energética, dando preferência aos carboidratos e lipídeos (Silva et al., 2003).

O balanço energia-proteína, a qualidade da proteína e a digestibilidade da fonte não proteica de energia são fatores que influenciam a exigência de proteína e energia do tambaqui (Vidal Júnior et al., 1998). Santos et al. (2010) verificaram melhor ganho de peso relativo, taxa de crescimento específico e eficiência alimentar de juvenis de tambaqui alimentados até a saciedade aparente, submetidos a 14 dias de privação alimentar, em comparação ao tratamento sem privação alimentar. Os autores relataram ainda que as exigências proteicas não são aumentadas após privação alimentar. Os níveis proteicos estudados, o peso inicial dos juvenis, os níveis de energia das dietas utilizadas em suas avaliações e o nível proteico sugerido por esses autores são sumarizados na Tabela 1.

Dietas contendo baixo nível proteico ou alta relação energia/PB favorecem a deposição de gordura nos peixes. Como boa parte dessa gordura se deposita na cavidade abdominal resulta em menor rendimento de carcaça e maior proporção de resíduos no processamento. Também, a alimentação excessiva, o desequilíbrio em aminoácidos essenciais, deficiências de minerais e vitamínicas são fatores que favorecem a deposição de gordura visceral (Kubitza, 2009). Rodrigues (2014) relataram que o excesso de energia pode reduzir o consumo de ração pelos tambaquis e, consequentemente, de outros nutrientes.

Por outro lado, a deficiência, pode conduzir o metabolismo à utilização de proteína dietética como fonte de energia. Assim, Camargo et al. (1998) ao fornecerem níveis crescentes de energia metabolizável $(2,85 ; 3,00 ; 3,15$ e 3,30 Kcal de EM.g ${ }^{-1}$, com $24 \%$ de PB) para tambaquis de peso vivo inicial médio de $30 \mathrm{~g}$, cultivados em tanques e alimentados duas vezes ao dia à taxa de 3,00\% da biomassa, observaram aumento linear da taxa de deposição de proteína na carcaça.

Os autores atribuíram esses resultados ao efeito "poupador de proteína" como fonte de energia e também devido à maior quantidade de energia disponível para síntese e deposição proteica. $\mathrm{O}$ maior nível energético da dieta resultou em melhores resultados de ganho de peso, conversão alimentar aparente e taxa de deposição proteica. Por fim, recomendaram razão energia:proteína entre 12,50 e $13,75 \mathrm{Kcal}_{\mathrm{g}}{ }^{-1}$.

Trabalhos realizados com intuito de determinar o nível de proteína bruta da ração para tambaquis apresentam resultados contraditórios, o que dificulta unanimidade quanto as recomendações, para as diversas fases de desenvolvimento. Essas diferenças podem ser explicadas pela composição das rações, as condições ambientais durante a condução dos estudos, a frequência e taxa de alimentação empregada, a presença de alimentos naturais e outras peculiaridades de cada ensaio (Tabela 1) (Kubitza, 2009). Vidal Júnior et al. (1998) sugeriram que altos teores de proteína bruta influenciaram negativamente a deposição proteica na carcaça, sendo essa, utilizada principalmente como fonte de energia, quando alimentaram alevinos de tambaqui, à taxa de $3,00 \%$ da biomassa, em duas refeições diárias.

Gutiérrez et al. (2009) alimentaram juvenis de tambaqui até a saciedade aparente, duas vezes ao dia e verificaram melhoria no ganho de peso, conversão alimentar e da energia retida quando trabalharam com níveis de $25,00 \%$ de proteína bruta e nível de energia digestível (ED) de 2,70 Kcal.g ${ }^{-1}$.

Vásquez-Torres et al. (2011) no intuito de determinarem o requerimento ótimo de proteína em dietas para juvenis de pirapitinga, alimentados duas vezes ao dia até a saciedade aparente, forneceram dietas semipurificadas, à base de caseína e gelatina com níveis crescentes de PB. Esses autores verificaram maior ganho de peso, taxa de crescimento específico e melhor conversão alimentar com dieta contendo $32,00 \%$ de PB. Utilizando-se os dados de ganho de peso para definição de modelos de regressão polinomial, os autores sugeriram $31,6 \%$ de PB na dieta para ótimo ganho de peso da pirapitinga. A taxa de eficiência proteica foi negativamente correlacionada com os níveis de PB da dieta, relacionada ao "efeito poupador de proteína" do Piaractus brachypomus. Esses autores relataram que uma espécie de peixe quando alimentada até a 
saciedade sofre influência da capacidade de ingestão de alimento para adequado ganho de peso, não dependendo somente dos níveis de energia e de nutrientes da dieta.

Tabela 1 - Níveis de proteína bruta (PB), energia e relação energia:proteína para Colossoma macropomum em diferentes fases em sistema de cultivo laboratorial (tanques).

\begin{tabular}{|c|c|c|c|c|c|}
\hline Referências & Peso inicial (g) & $\begin{array}{c}\text { Níveis avaliados } \\
\text { de PB }(\%)\end{array}$ & $\begin{array}{l}\text { Nível de PB (\%) } \\
\text { sugerido }\end{array}$ & $\begin{array}{l}\text { Nível de energia das } \\
\text { dietas }\left(\text { Kcal.g }^{-1}\right)\end{array}$ & $\begin{array}{c}\text { Relação } \\
\text { energia/proteína } \\
\left.\text { sugerida (Kcal.g }{ }^{-1}\right)\end{array}$ \\
\hline Vidal Júnior et al. (1998) & 30 & 18 a 30 & 25 & $3,10 \mathrm{EM}$ & 11,48 a $12,92 \mathrm{EM} / \mathrm{PB}$ \\
\hline$\underline{\text { Gutiérrez et al. (2009) }}$ & 50 & 25 e 35 & 25 & 2,30 a $2,70 \mathrm{ED}$ & $10,80 \mathrm{ED} / \mathrm{PB}$ \\
\hline$\underline{\text { Santos et al. (2010) }}$ & 50 & 28 a 40 & 36 & 3,20 a $3,40 \mathrm{ED}$ & $9,50 \mathrm{ED} / \mathrm{PB}$ \\
\hline
\end{tabular}

ED: Energia digestível; EM: Energia metabolizável.

Kubitza (1999) recomendou para peixes redondos, com peso corporal entre 1,00 e $30,00 \mathrm{~g}$ nível de 36,00 a 40,00\% de PB. Após $30 \mathrm{~g}$ de peso vivo, até que esses atinjam $500 \mathrm{~g}$, esse mesmo autor sugeriu utilização de ração contendo 32 a $36 \%$ de PB. Essa mesma referência sugeriu para peixes redondos com mais de $500 \mathrm{~g}$ nível de 28 a $32 \%$ de PB na ração.

As sugestões de Kubitza (1999) superam as apresentadas na Tabela 2, por demais pesquisadores. Assim como relatado por VásquezTorres et al. (2011) a capacidade de ingestão pode influenciar essas recomendações. Além disso, é importante considerar a quantidade de nutriente ingerida em $\mathrm{g} / \mathrm{dia}$ em detrimento da concentração de nutriente em si na dieta, pois a primeira, é resultante da combinação da concentração do nutriente e a taxa de alimentação diária. Kubitza (1999) relatou ainda, que a redução demasiada no conteúdo proteico da dieta com o aumento do peso vivo dos peixes pode resultar em acúmulo de gordura nas vísceras e na carcaça.
Vásquez-Torres et al. (2012) avaliaram o desempenho e parâmetros bioquímicos plasmáticos de juvenis de pirapitinga recebendo dietas contendo diferentes níveis de PD em três diferentes condições de cultivo: laboratorial, em sistema de recirculação de água; em gaiolas $\left(2 \mathrm{~m}^{3}\right)$ alocadas em represa (100 juvenis. $\left.\mathrm{m}^{-3}\right)$. Nas condições laboratoriais e nas gaiolas, à medida que o conteúdo proteico das dietas aumentou, a taxa de eficiência proteica piorou.

Os parâmetros bioquímicos foram influenciados pelos tratamentos nas condições laboratoriais, verificando-se redução dos níveis de ureia e colesterol com aumento dos níveis de proteína da dieta. Os autores sugeriram valores de PD de 24,00 e $26,00 \%$ equivalentes a 27,70 e $30,00 \%$ de PB (Tabela 2). Esses valores de PD sugeridos foram suficientes para o ótimo desenvolvimento da pirapitinga independentemente do ambiente de cultivo.

Tabela 2. Níveis de proteína, energia e relação energia:proteína para Piaractus brachypomus.

\begin{tabular}{|c|c|c|c|c|c|c|}
\hline Autor & $\begin{array}{l}\text { Peso } \\
\text { inicial } \\
(\mathrm{g})\end{array}$ & $\begin{array}{c}\text { Níveis } \\
\text { proteicos }(\%) \\
\text { avaliados }\end{array}$ & $\begin{array}{l}\text { Nível de } \\
\text { proteína (\%) } \\
\text { sugerido }\end{array}$ & $\begin{array}{c}\text { Nível de energia } \\
\text { das dietas } \\
\left(\text { Kcal.g }^{-1}\right)\end{array}$ & $\begin{array}{c}\text { Relação } \\
\text { energia/proteína } \\
\text { sugerida (Kcal.g }{ }^{-1}\end{array}$ & $\begin{array}{l}\text { Sistema de } \\
\text { cultivo }\end{array}$ \\
\hline Vásquez-Torres et al. (2011) & 15,52 & 16 a $36 \mathrm{~PB}$ & $31,60 \mathrm{~PB}$ & 5,42 a $5,52 \mathrm{~EB}$ & $17,15 \mathrm{~EB} / \mathrm{PB}$ & Tanque \\
\hline Vásquez-Torres et al. (2012) & 21 & 24 a 34 PD & $24 \mathrm{PD}$ & 4,53 a 4,64 EB & $18,90 \mathrm{~EB} / \mathrm{PD}$ & Laboratorial \\
\hline $\begin{array}{l}\text { Vásquez-Torres \& Arias- } \\
\text { Castellanos (2013) }\end{array}$ & 29 a 65 & 26 a 34 PD & $26 \mathrm{PD}$ & 4,42 a $4,47 \mathrm{~EB}$ & $17,01 \mathrm{~EB} / \mathrm{PD}$ & $\begin{array}{l}\text { Gaiolas e viveiro } \\
\text { escavado }\end{array}$ \\
\hline
\end{tabular}

PB: Proteína bruta; PD: Proteína digestível; EB: Energia bruta.

\section{Aminoácidos essenciais}

$\mathrm{Na}$ piscicultura tecnificada a formulação de dietas não se baseia somente nos níveis de proteína bruta, mas sim, com a adequação das exigências dos aminoácidos essenciais e utilização de aminoácidos sintéticos, permitindo, em alguns casos, redução do nível de $\mathrm{PB}$ da ração que podem tornar-se excessivos. A absorção de proteína ocorre em boa parte na forma de aminoácidos, em 
co-transporte dependente de $\mathrm{Na}^{+}$, transportadores não dependentes de $\mathrm{Na}^{+}$e por difusão, em certas ocasiões, na dependência de transportadores específicos (Rotta, 2003).

Quando dois ou mais aminoácidos são absorvidos pelo mesmo transportador, a presença de grande quantidade de um deles pode inibir a absorção do outro (competição pelo sítio de absorção). Em alguns teleósteos o transporte de metionina, valina e treonina competem entre si (Baldisserotto, 2013). Para adequado desenvolvimento, os peixes necessitam de mistura balanceada de aminoácidos essenciais e não essenciais. Para rações formuladas com predominância de proteína de origem animal, a lisina, os aminoácidos sulfurados, treonina e triptofano são os primeiros limitantes (Cavalheiro et al., 2014). Nesse sentido, Brandão et al. (2009) avaliaram os benefícios da redução do nível de proteína bruta $(20$ e $25 \%)$ a partir da suplementação ou não de metionina (3\% da PB) e/ou lisina (5\% da PB) sobre a excreção de amônia total por juvenis de tambaqui. Esses autores não observaram benefício da adição de lisina e/ou metionina sintéticas, com relação à excreção de amônia total. Entretanto, com a redução do nível proteico da dieta, a excreção de amônia total reduziu $28,40 \%$. Esses resultados sinalizam para o benefício da redução do nível proteico da dieta quanto a excreção de amônia e adequação nutricional com a suplementação com aminoácidos essenciais.

Vásquez-Torres \& Arias-Castellanos (2013) formularam nove dietas isoproteicas e isocalóricas para alevinos de Piaractus brachypomus, com peso médio inicial de $10,8 \mathrm{~g}$, através da substituição de gelatina por caseína. Os níveis de inclusão de caseína variaram entre 0,00 e 35,00, no intuito de provocar alterações nas proporções relativas dos AAE das dietas e determinar a sequência de aminoácidos limitantes para a pirapitinga. $\mathrm{O}$ ganho de peso e a taxa de crescimento específico foram positivamente correlacionados com a inclusão de caseína. A taxa de eficiência proteica também aumentou proporcionalmente à inclusão de caseína.

Para inclusões de caseína de até $4,40 \%$, apenas para arginina não se verificou escore químico $(\mathrm{SQ})=((\% \mathrm{AAE}$ da dieta/\% AAE da carcaça $) \mathrm{x}$ $100)$ inferior a 100 , sendo o primeiro aminoácido limitante, nessas condições, isoleucina seguida da metionina. Entre inclusões de 8,8 e 17,5\% de caseína observou-se SQ superior a 100, somente para arginina e valina, sendo os primeiros aminoácidos limitantes, nessas condições, treonina e metionina. Todavia, para inclusões de caseína abaixo de $17,5 \%$ praticamente todos os aminoácidos foram limitantes. Com níveis de inclusão de 21,9\% de caseína observou-se redução do SQ para valores inferiores a 100, para arginina, sendo nessas condições, os aminoácidos treonina, arginina e metionina os que apresentaram menor SQ. Quando se incluiu 26,20\% de caseína, apenas os SQ da arginina e treonina foram inferiores a 100 , indicando maior adequação nutricional, conforme o SQ's calculados. Os resultados demonstram que apesar da caseína ser uma proteína de alta qualidade, seu perfil de AAE não é suficiente para atender às necessidades quantitativas para máximo crescimento quando utilizado como única fonte proteica para a pirapitinga.

\section{Minerais}

De acordo com Dairiki \& Silva (2011) a maioria dos macrominerais e microminerais como cálcio, magnésio, sódio, potássio, ferro, zinco, cobre e selênio são absorvidos diretamente da água de cultivo para sua manutenção e crescimento. Porém muitos desses não são absorvidos em quantidades suficientes para o desempenho desejado. Exemplo disso é o ferro que deve ser adicionado à ração por desempenhar papel importante na formação da hemoglobina, mioglobina, transferrina, ferritina, entre outras proteínas. As poucas pesquisas relacionadas à suplementação de minerais em espécies nativas se concentram nos macros minerais cálcio e fósforo, sendo esses obtidos através da água de cultivo e principalmente do alimento, advindo de ingredientes minerais ou farinhas de origem animal. Em fontes de origem vegetal o elemento fósforo é encontrado principalmente na forma de fitato, sendo benéfica a inclusão da enzima fitase, para sua disponibilização aos peixes. Neste sentido, Mendonça et al. (2012) avaliaram a reposta de alevinos de tambaqui com $3,12 \mathrm{~g}$ de peso vivo inicial à suplementação com níveis crescentes dessa enzima (700, 1400, 2100 e 2800 de unidades de fitase ativa - UFA. $\mathrm{kg}^{-1}$ ). De acordo com os modelos de regressão ajustados utilizandose dos dados das variáveis de consumo de ração, conversão alimentar aparente e taxa de eficiência proteica, os níveis de suplementação determinados foram, respectivamente, de 1540,62; 1796,90 e 1760,35 UFA. $\mathrm{kg}^{-1}$. Os autores mencionaram, também, que a ação e o resultado dos níveis de 
fitase empregados estão relacionados com o valor biológico dos alimentos, a natureza e a quantidade de ácido fítico que esses possam conter.

\section{Vitaminas}

As vitaminas são nutrientes orgânicos essenciais nas várias reações do metabolismo, o organismo não tem condições de produzir e, por isso, precisam fazer parte da dieta alimentar. Em sua deficiência surgem as chamadas doenças da carência (avitaminose). São classificadas quanto à solubilidade, em vitaminas lipossolúveis e hidrossolúveis. Em se tratando de vitaminas hidrossolúveis, a vitamina $\mathrm{C}$ merece especial atenção, pois não pode ser sintetizada pelos teleósteos, devido à ausência da enzima Lgulonolactona oxidase.

Nesse sentido, Chagas \& Val (2003) suplementaram a ração de juvenis de tambaqui, de peso médio inicial de $33,77 \mathrm{~g}$, com níveis crescentes $(0 ; 100$ e 500 ppm $)$ de ácido Lascórbico, não protegido e/ou estabilizado e verificaram maior sobrevivência, ganho de peso e melhor conversão alimentar quando os peixes foram alimentados com 100 ppm. Verificaram ainda que níveis limitantes dessa vitamina podem causar redução do hematócrito e da contagem de eritrócitos. Dessa maneira, esses autores sugeriram para o tambaqui, suplementação mínima de 100ppm de ácido L-ascórbico, não protegido e/ou estabilizado na dieta.

\section{Enzimas}

Além da necessidade do conhecimento dos valores nutricionais dos alimentos a serem utilizados nas dietas, outras estratégias podem e vêm sendo utilizadas, no sentido de aumentar a eficiência de utilização das dietas pelos tambaquis.

Silva et al. (2007) avaliaram os coeficientes de digestibilidade aparente da $\mathrm{PB}$, extrato etéreo (EE), carboidratos ( $\mathrm{CHO})$ e EB ao incluir níveis crescentes $(0,00 ; 0,05 ; 0,10$ e $0,15 \%)$ de complexo enzimático contendo levedura seca, amilase, protease, lipase e celulase, na ração de tambaquis com peso médio inicial de $150 \mathrm{~g}$. Esses autores verificaram melhoria de 19,$6 ; 15,7 ; 35,1$ e $33,5 \%$, sobre os coeficientes de digestibilidade aparentes da $\mathrm{PB}, \mathrm{EE}, \mathrm{CHO}$ e EB, respectivamente, ao incluir $0,05 \%$ desse complexo enzimático. Os autores ponderaram ainda, para outros benefícios da inclusão desse produto na dieta, no tocante à melhoria da conversão alimentar, redução na produção de dejetos, que concorre para redução da carga poluente da atividade e da qualidade da água de cultivo. Nunes et al. (2006) também avaliaram os efeitos de diferentes níveis de inclusão $(0,00$; 0,$05 ; 0,10$ e $0,20 \%$ ) de enzimas, de forma isolada, (amilase, lipase e protease) na ração de juvenis de tambaqui. Os níveis $0,05 \%$ de amilase e $0,20 \%$ lipase na ração resultaram em melhor ganho de peso, conversão alimentar aparente e taxa de crescimento específico, de tambaquis com peso vivo inicial entre 12,43 e 19,82g. A inclusão isolada da protease na dieta de tambaquis com $23,8 \mathrm{~g}$ de peso vivo inicial, não influenciou o desempenho zootécnico. Esses resultados permitiram com que os autores concluíssem a respeito da otimização do uso da proteína quando os requerimentos calóricos são alcançados, assim como relatado por Espinós et al. (2003) que observaram que as exigências proteicas de peixes podem reduzir com o melhor aproveitamento dos lipídeos.

\section{Lipídeos}

Os lipídeos exercem diversas funções metabólicas, além de importantes fontes de energia, são também consideráveis fontes de ácidos graxos essenciais, proporcionam maior palatabilidade à ração, atuam como fonte de energia para a reprodução e desempenham papel fundamental na utilização eficiente das proteínas para crescimento (Dairiki \& Silva, 2011).

Outra função lipídica de grande influência no desempenho do tambaqui é o fato de atuar como veículo para vitaminas lipossolúveis e esteróis. Havendo ainda o benefício de serem armazenadas no tecido adiposo e fígado, e consequentemente não dependerem de suplementação diária, ao contrário das vitaminas hidrossolúveis que em geral não podem ser armazenadas. Entretanto, como o cultivo de organismos aquáticos ocorre na dependência de água para tal, há solubilização destas vitaminas antes mesmo da ração ser consumida pelos peixes, podendo, em alguns casos, caracterizar sua deficiência (Kubitza, 1999).

As fontes de energia utilizadas na dieta do Piaractus brachypomus podem influenciar diretamente o aproveitamento da fração proteica da dieta. Vásquez-Torres (2001) ao de determinar os efeitos de dietas com diferentes proporções de carboidratos (20; 28 e 36\%) e lipídeos ( $4 ; 8$ e $12 \%)$ sobre o crescimento de juvenis $(7,8 \mathrm{~g})$ de Piaractus brachypomus forneceram nove dietas 
isoproteicas (32\% de PB) contendo valores de energia bruta variando entre 5,00 e 5,40 Kcal.g ${ }^{-1}$, observou que o aumento dos níveis de lipídeos em dietas contendo baixos níveis de carboidratos (20\%) prejudicaram o ganho de peso dos peixes.

Ao contrário, verificou-se que a redução do nível de lipídeos em dietas contendo altos níveis de carboidratos foi benéfica para a melhoria do ganho de peso dos peixes. Os autores relataram que os melhores resultados de ganho de peso foram decorrentes da alimentação dos peixes com dietas contendo razões de carboidratos:lipídeos entre 5 e 9 , porém a máxima porcentagem de retenção de proteína foi constatada com relação de 4,5. Relatou-se ainda redução no consumo de alimento à medida que o conteúdo de carboidrato da dieta aumentou.

\section{Alimentos alternativos}

Com toda variedade de espécies nativas brasileiras, alguns hábitos alimentares podem ser verificados, sendo os mais comuns, os peixes detritívoros, herbívoros, carnívoros e onívoros. Dentro dessas categorias, ainda podem ser classificados em eurífagos, estenófagos ou monófagos. Esta segunda classificação diz respeito à variedade de alimentos consumidos pela espécie, as quais consomem grande variedade de alimentos, pequena variedade de alimentos e apenas um tipo de alimento, respectivamente (Baldisserotto, 2013). O emprego de dietas nutricionalmente eficientes e de baixo custo são fundamentais para o sucesso do processo produtivo de uma piscigranja em razão dos custos com alimentação representar de 50 a $80 \%$ dos custos de produção. Dietas menos onerosas podem ser obtidas com o emprego de ingredientes de baixo valor comercial, que comumente ligado a grande disponibilidade desse produto ou coproduto no mercado.

Lemos et al. (2011) avaliaram a substituição do farelo de soja pelo farelo de coco e verificaram modificações no desempenho de alevinos de tambaqui, para níveis de substituição acima de $25,00 \%$ do farelo de soja. Desse modo, é de suma importância o conhecimento dos valores nutricionais dos alimentos utilizados na dieta e a eficiência de utilização destes pelas diferentes espécies de peixes que podem ser extremamente variáveis. Cruz et al. (1997) avaliaram o desempenho de alevinos de tambaqui $(1,12 \mathrm{~g})$ alimentados com duas rações, uma contendo inclusão de coprodutos da produção de cerveja, malte e cevada e outra, ração comercial extrusada. As rações apresentaram, respectiva-mente, 36 e $34 \%$ de PB; 3,90 e 3,65 Kcal.g ${ }^{-1}$ de energia bruta (EB). Os peixes foram alimentados duas vezes ao dia, na proporção de $6,00 \%$ da biomassa. A ração comercial proporcionou melhor ganho de peso e comprimento padrão dos peixes. Todavia, a conversão alimentar e a sobrevivência não foram influenciados pelos tratamentos. Dessa forma os autores ponderaram para a possibilidade da inclusão parcial dos coprodutos da produção de cerveja na ração do tambaqui, o que possibilita redução nos custos com alimentação.

Lopes et al. (2010) avaliaram o desempenho produtivo de juvenis $(24 \mathrm{~g})$ de tambaqui alimentados com rações, peletizadas, isoproteicas e isoenergéticas (26\% de PB e 3,20 Kcal de ED.g1) com três níveis de inclusão de farelo de babaçu (0; 6 e 12\%). A ração foi fornecida três vezes ao dia, até a saciedade aparente. Os níveis de inclusão de farelo de babaçu não influenciaram o ganho de peso, o consumo de ração, a conversão alimentar aparente, o rendimento de carcaça e o rendimento de filé dos juvenis. O índice hepatosomático, por outro lado, reduziu à medida que se aumentou a inclusão do farelo de babaçu. Esse índice pode ser utilizado como parâmetro para avaliação das reservas energéticas dos peixes, ainda, pode indicar exposição à ação de fatores antinutricionais presentes nos alimentos. Todavia, os autores sugeriram que a inclusão máxima de farelo de babaçu estudada (12\%) pode ser praticada em dietas de juvenis de tambaqui.

\section{Considerações Finais}

Para as espécies nativas mencionadas no presente trabalho existe vasta quantidade de publicações relevantes. Porém, no que diz respeito a determinação das exigências nutricionais de aminoácidos essenciais, ácidos graxos essenciais, vitaminas e minerais essas informações são escassas. Ainda, há necessidade de aprofundar os conhecimentos sobre a digestibilidade das frações proteica e da energia dos diversos alimentos incluídos na alimentação dessas espécies. Os níveis proteicos e energéticos exigidos pelas espécies também devem ser melhor esclarecidos, pois não há concordância entre os resultados de pesquisas. A nutrição é a base para a lucratividade de uma piscigranja que cultiva espécies de peixes nativos, sendo necessários conhecimentos dos alimentos, manejo alimentar e particularidades de cada espécie para desempenho satisfatório. Entre as espécies estudadas, a que possui maior carência 
de resultados de pesquisa voltados a nutrição é a Piaractus brachypomus. Devem-se priorizar estudos nutricionais com dietas práticas que investiguem os níveis adequados de inclusão de carboidratos e lipídeos como fontes energéticas na formulação de rações, implicando possível redução do nível proteico.

\section{Referências Bibliográficas}

Abimorad, E. G., Carneiro, D. J. \& Urbinati, E. C. 2007. Growth and metabolism of pacu (Piaractus mesopotamicus Holmberg 1887) juveniles fed diets containing different protein, lipid and carbohydrate levels. Aquaculture Research, 38, 36-44.

Baldisserotto, B. 2013. Fisiologia de peixes aplicada à piscicultura. Universidade Federal de Santa Maria, Santa Maria.

Boscolo, W. R., Signor, A., Freitas, J. M. A., Bittencourt, F. \& Feiden, A. 2011. Nutrição de peixes nativos. Revista Brasileira Biociências, 40, 145-154.

Brandão, L. V., Pereira-Filho, M., Guimarães, S. F. \& Fonseca, F. A. L. 2009. Suplementação de metionina e/ou lisina em rações para juvenis de tambaqui (Colossoma macropomum Cuvier, 1818). Acta Amazonica, 69, 675-680.

BRASIL. Anuário Brasileiro da Pesca e Aquicultura (ABPA). 2014. Futuro próspero: Quantidade de água disponível, clima e geografia favoráveis à aquicultura, além de uma grande biodiversidade e fronteiras de pesca extrativa ainda não exploradas podem tornar o Brasil um dos grandes produtores do setor. Associação Cultural e Educacional Brasil - ACEB. $1^{a}$ ed.

BRASIL. Ministério da pesca E aquicultura. 2011. Boletim estatístico da pesca e aquicultura do Brasil. Brasília, 69 p.

BRASIL. Plano nacional de recursos hídricos. Rios e bacias do Brasil formam uma das maiores redes fluviais do mundo. 2014. Disponível em: http://www.brasil.gov.br/meio ambiente/2009/10/rios-e-bacias-do-brasilformam-uma-das-maiores-redes-fluviais-domundo Acesso: 19 Abril 2016.

Camargo, A. C. S., Júnior, M. V. V., Donzele, J. L., Andrade, D. R. \& Santos, L. C. 1998. Níveis de energia metabolizável para tambaqui (Colossoma macropomum) dos 30 aos 180 gramas de peso vivo. 1. Composição das carcaças. Revista Braseleira de Zootecnia, 27, 409-415.

Cavalheiro, A. C. M., Einhardt, M. D. S., Pouey, J. L. O. F., Piedras, S. N. \& Xavier, E. G. 2014. Microingredientes utilizados em alimentação de peixes em cativeiro. Revista Portuguesa de Ciencias Veterinarias, 11, 11-20.

Chagas, E. C., Carvalho, G. L., Júnior, H. M., Roubach, R. \& Paula Lourenço, J. N. 2005. Desempenho de tambaqui cultivado em tanques-rede, em lago de várzea, sob diferentes taxas de alimentação. Pesquisa Agropecuária Brasileira, 40, 833-835.

Chagas, E. C. \& Val, A. L. 2003. Efeito da vitamina $\mathrm{C}$ no ganho de peso e em parâmetros hematológicos de tambaqui. Pesquisa Agropecuária Brasileira, 38, 397-402.

Costa, A.C. Imputação de parentesco genético e predição das capacidades cominatórias em sulrrsalmildes. Tese. (Doutorado). Departamento de Produção e Nutrição de Não Ruminantes. Lavras, 117 p.

Cruz, W. D., Miguel, C. B., Bonifácio, A. D., Reis, F. A. \& Fialho, A. P. 1997. Resíduo de cervejaria na alimentação de tambaqui, Colossoma macropomum (Cuvier, 1818). Boletim do Instituto de Pesca, 24, 133-138.

Dairiki, J. K. \& Silva, T. B. A. 2011. Revisão de literatura: exigências nutricionais do tambaqui-compilação de trabalhos, formulação de ração adequada e desafios futuros. In: EMBRAPA (ed.) Manaus: Embrapa Amazônia Ocidental. Manaus.

Espinós, F. J., Tomás, A., Pérez, L. M., Balasch, S. \& Jover, M. 2003. Growth of dentex fingerlings (Dentex dentex) fed diets containing different levels of protein and lipid. Aquaculture, 218, 479-490.

Gutiérrez, A., Walter, F., Zaldívar, R. \& Contreras, S. 2009. Efecto de varios niveles de energía digestible y proteína en la dieta sobre el crecimiento de Gamitana (Colossoma macropomum) Cuvier 1818. Revista de Investigaciones Veterinarias del Perú, 20, 178186.

Kubitza, F. 1999. Nutrição e alimentação dos peixes cultivados, Campo Grande, Mato Grosso do Sul.

Kubitza, F. 2009. Manejo na produção de peixes. Panorama da Aqüicultura, 19, 14-23. 
Lemos, M. V. A., Guimarães, I. G. \& Miranda, E. C. 2011. Farelo de coco em dietas para o tambaqui (Colossoma macropomum). Revista Brasileira de Saúde e Produção Animal, 12, 188-198.

Lima, M. C. d. C. 2014. Desenvolvimento embrionário e larval de Colossoma macropomum, Piaractus brachypomus e do híbrido tambatinga. Departamento de Zootecnia. Universidade Federal de Goiás, Goiânia.

Lopera-Barreto, N. M., Ribeiro, R. P., Povh, J. A., Vargas-Mendez, L. D. \& Poveda-Parra, A. R. 2011. Produção de organismos aquáticos: uma visão geral no Brasil e no mundo. Guaíba: Agrolivros.

Lopes, J. M., Pascoal, L. A. F., Silva Filho, F. P., Santos, I. B., Watanabe, P. H., Araujo, D. d. M., Pinto, D. C. \& Oliveira, P. S. 2010. Farelo de babaçu em dietas para tambaqui. Revista Brasileira de Saúde e Produção Animal, 11.

Mendonça, P. P., Costa, P. C., Polese, M. F., Vidal Jr, M. V. \& Andrade, D. R. 2012. Efeito da suplementação de fitase na alimentação de juvenis de tambaqui (Colossoma macropomum). Archivos de Zootecnia, 61, 437-448.

Neves, M., Balen, R. E., Meurer, F., Baumgartner, G. \& Braga, A. F. 2015. Exigência de proteína digestível para alevinos de Pacu (Piaractus mesopotamicus) alimentados com ração à base de farelo de soja. Agrarian, 8, 204-209.

Nunes, E. S. S., Cavero, B. A. S., Pereira-Filho, M. \& Roubach, R. 2006. Enzimas digestivas exógenas na alimentação de juvenis de tambaqui. Pesquisa Agropecuária Brasileira, 41, 139-143.

Rodrigues, A. P. O. 2014. Nutrição e alimentação do tambaqui (Colossoma macropomum). Boletim do Instituto de Pesca, 40, 135-145.

Rotta, M. A. 2003. Aspectos gerais da fisiologia e estrutura do sistema digestivo dos peixes relacionados à piscicultura. EMBRAPA. Embrapa Pantanal, Corumbá.

Santos, L., Pereira Filho, M., Sobreira, C., Ituassú, D. \& Fonseca, F. A. L. 2010. Exigência protéica de juvenis de tambaqui (Colossoma macropomum) após privação alimentar. Acta Amazonica, 40, 597-604.
Silva, J. A. M., Pereira-Filho, M., Cavero, B. A. S. \& Oliveira-Pereira, M. I. 2007. Digestibilidade aparente dos nutrientes e energia de ração suplementada com enzimas digestivas exógenas para juvenis de tambaqui (Colosssoma macropomum Cuvier, 1818). Acta Amazonica, 37, 157-164.

Silva, J. A. M., Pereira-Filho, M. \& OliveiraPereira, M. I. 2003. Frutos e sementes consumidos pelo tambaqui, Colossoma macrompum (Cuvier, 1818) incorporados em rações. Digestibilidade e velocidade de trânsito pelo trato gastrointestinal. Revista Braseleira de Zootecnia, 32, 1815-1824.

Vásquez-Torres, W., Hernández-Arévalo, G., Gutiérrez-Espinosa, M. C. \& Yossa, M. I. 2012. Efecto del nivel de proteína dietaria sobre el crecimiento y parámetros séricos en cachama blanca (Piaractus brachypomus). Revista Colombiana de Ciencias Pecuarias, 25, 450-461.

Vásquez-Torres, W., Pereira-Filho, M. \& AriasCastellanos, J. A. 2011. Optimum dietary crude protein requirement for juvenile cachama Piaractus brachypomus. Ciência Rural, 41, 2183-2189.

Vásquez-Torres, W. \& Arias-Castellanos, J. A. 2013. Crescimento de juvenis de Piaractus brachypomus alimentados com dietas contendo diferentes perfis de aminoácidos essenciais. Pesquisa Agropecuária Brasileira, 48, 849-856.

Vidal Júnior, M. V., Donzele, J. L., Silva Camargo, A. C., Andrade, D. R. \& Santos, L. C. 1998. Níveis de proteína bruta para tambaqui (Colossoma macropomun), na fase de 30 a 250 gramas. 1. Desempenho dos tambaquis. Revista Braseleira de Zootecnia, $27,421-426$.

\section{Article History:}

Received 18 September 2016

Accepted 6 October 2016

Available on line 4 November 2016

License information: This is an open-access article distributed under the terms of the Creative Commons Attribution License 4.0, which permits unrestricted use, distribution, and reproduction in anymedium, provided the original work is properly cited. 